\title{
Safety protocols for dental care during the COVID-19 pandemic: the experience of a Brazilian hospital service
}

\author{
Alessandra Figueiredo SOUZA ${ }^{(a)}$ \\ José Alcides Almeida de \\ ARRUDA $^{(a)}$
Fernanda Pereira Delgado $\operatorname{costa}^{(b)}$ iD \\ Larissa Marques BEMQUERER(a) \\ Wagner Henriques CASTRO(a) \\ Felipe Eduardo Baires CAMPOS(a) \\ Fabiana Maria KAKEHASI(c) \\ Denise Vieira TRAVASSOS(d) \\ Tarcília Aparecida SILVA(a)
}

(a) Universidade Federal de Minas Gerais UFMG, School of Dentistry, Department of Oral Surgery, Pathology and Clinical Dentistry, Belo Horizonte, MG, Brazil

(b) Universidade Federal de Minas Gerais UFMG, Hospital das Clínicas, Dental Surgeon Residency, Belo Horizonte, MG, Brazil

(c) Universidade Federal de Minas Gerais UFMG, School of Medicine, Department of Pediatrics, Belo Horizonte, MG, Brazil

(d) Universidade Federal de Minas Gerais UFMG, School of Dentistry, Department of Community and Preventive Dentistry, Belo Horizonte, MG, Brazil

Declaration of Interests: The authors certify that they have no commercial or associative interest that represents a conflict of interest in connection with the manuscript.

\section{Corresponding Author:}

Tarcília Aparecida Silva

E-mail: silva.tarcilia@gmail.com;

tarcilia@ufmg.br

ht1ps://doi.org/10.1590/1807-3107bor-2021.vol35.0070

Submitted: December 3, 2020

Accepted for publication: March 1, 2021

Last revision: April 22, 2021
Abstract: The coronavirus disease (COVID-19) has been prioritized in relation to other illnesses considered critical, such as cancer, cardiovascular diseases/stroke, diabetes, and autoimmune diseases. The management of patients with these diseases involves dental care to reduce systemic complications caused by odontogenic infections, and/or to treat oral manifestations of systemic comorbidities. In this regard, the dental care of these individuals must be guaranteed during the pandemic. Although a high risk of exposure to and catching of COVID-19 is expected to befall dental professionals, biosafety guidelines reduce the likelihood of infection. Thus, the current scenario poses challenges, and offers decision-making approaches and tools that facilitate the management of individuals with oral manifestations of chronic and/or critical diseases, using hospital-based services. This article presents an overview for hospital service providers who are at the forefront of COVID-19 care, including a secure protocol, and clinical guidelines based on the experience of the Hospital das Clínicas in Belo Horizonte, a public referral service, supported by the Brazilian National Health System.

Keywords: COVID-19; Dental Care; Dental Service, Hospital; Personal Protective Equipment; SARS-CoV-2.

\section{Introduction}

Ever since the initial coronavirus disease (COVID-19) outbreak in late December 2019, in Wuhan, Hubei province, China, and as of March 11, 2020, when the World Health Organization (WHO) declared the severe, acute respiratory syndrome coronavirus 2 (SARS-CoV-2) as a global pandemic, the disease has become a global threat with a dramatic impact on healthcare systems. ${ }^{1,2}$ The first confirmed case of COVID-19 in Brazil was reported on February 21, 2020. ${ }^{3}$ Since then, this nation has become the new epicenter of COVID-19, totaling more than 6.3 million cases and over 172,800 deaths by the end of November 2020. Although efforts have been made to reduce transmission of the epidemic and evolutionary trajectories of SARS-CoV-2 lineages in Brazil, current interventions are still insufficient to keep transmission of the virus under control in the country. ${ }^{4}$ 
The concerns and fears of dentists in Brazil and worldwide regarding professional practice during the COVID-19 pandemic are notorious. ${ }^{5,6}$ By mid-April 2020, 278 physicians worldwide had died from COVID-19.7 Among the providers working on the frontline, $6 \%$ were dentists. The countries with the largest number of reported deaths of health professionals have been Italy, Iran, the Philippines, Indonesia, China, Spain, the US, and the UK. ${ }^{7}$ These professionals succumbed to COVID-19 mainly due to the lack of personal protective equipment (PPE). ${ }^{7}$ Thus, the burden imposed by COVID-19 on health workers is overwhelming and undeniable. ${ }^{8}$

The unexpected circumstances of the pandemic caused the healthcare provided to patients with COVID-19 to be prioritized over the care for individuals with chronic diseases. ${ }^{9}$ Most importantly, the management of these individuals (e.g., patients with cancer, cardiovascular diseases/stroke, diabetes, autoimmune conditions, and others), in the different stages of their diseases, is interrelated with dental care, which aims to maintain oral health in order to reduce the risk of complications, and to improve the individual's overall quality of life. ${ }^{10,11}$ Dental care for these individuals is usually provided by hospital-based dental services. The main purpose of dental treatment for this population is to eradicate outbreaks of oral infection, prevent potentially fatal systemic infections of dental origin, ${ }^{12,13}$ relieve oral pain, assist in maintaining adequate nutrition, provide rehabilitation after surgical procedures ${ }_{,}^{10}$ and, more recently, as of the emergence of the pandemic, to diagnose and manage oral conditions, whether or not associated with COVID-19.14

It has been widely reported that the common routes of COVID-19 transmission include inhalation of droplets generated by coughs and sneezes from infected individuals, and by direct contact with their oral, nasal, and ocular mucosa. ${ }^{15}$ Moreover, there is a high probability of transmission of SARS-CoV-2 in dental care settings, from the dual risk of high aerosol-generating procedures, and the saliva of symptomatic and asymptomatic individuals. ${ }^{16}$ A study detected SARS-CoV-2 in the self-collected saliva of $91.7 \%$ of the individuals with positive RT-PCR, and determined that the virus remained viral positive even after long periods of infection..$^{17,18}$ In this scenario, working in the oral and maxillofacial field is considered to be at high risk of exposure to and catching of COVID-19. Providers who manipulate the particular anatomic region in question are at risk of infecting other patients, healthcare professionals, and their own families. ${ }^{19}$

Seeking to reduce infection by COVID-19, biosafety guidelines adhering to international protection standards have been proposed to be adopted before, during and after dental exposure to patients. To this end, evidence-based protocols must be established to safeguard professionals and patients - particularly those with chronic and/or critical diseases - whose dental care is pivotal to systemic health. We would like to contribute to this effort by providing a safe healthcare protocol and clinical guidelines, also based on the experience of the Hospital das Clínicas in Belo Horizonte, a Brazilian referral service for hospital-based dental service providers.

\section{Discussion}

\section{Hospital-based dental services}

The production of airborne material during dental practice is unavoidable, and represents a risk for the dental team and patients. ${ }^{20}$ Aerosols are defined as particles $\leq 50 \mu \mathrm{m}$ in diameter, ${ }^{20,21}$ implying that these particles are small enough to remain in the air for a long time before settling on environmental surfaces or entering the respiratory tract. Smaller aerosol particles ( 0.5 to $10 \mu \mathrm{m}$ in diameter) have the potential to penetrate and lodge themselves in the smaller passages of the lungs, and are believed to have the greatest potential for transmitting infections. ${ }^{20,21}$ There is evidence that dental aerosol can project out 1 to 3 meters from its source, contaminating distant surfaces. ${ }^{22}$ SARS-CoV-2 remains viable and can be detected up to 3 hours after aerosolization, and up to 7 days on different surfaces. ${ }^{23}$ The Centers for Disease Control and Prevention (CDC), and the American Dental Association (ADA) have recommended that aerosol-generating procedures should be avoided during the pandemic. ${ }^{24,25}$ There are at least three potential sources of airborne contamination during dental treatment: dental instrumentation, saliva and 
respiratory sources, and dental equipment (e.g., dental handpieces, ultrasonic scalers, air polishers and air abrasion units, the action of rotary instruments and ultrasonic vibrations, or the combined action of water jets and compressed air). ${ }^{20}$

Considering the characteristics of dental procedures, the focus is on emergency procedures during the pandemic. ADA and others Brazilian regulatory agencies, such as the Federal Council of Dentistry (CFO) and the Brazilian Health Surveillance Agency (ANVISA) - an agency connected to the Ministry of Health and belonging to the Brazilian National Health System (SUS) - recommend that dentists maintain an emergency, urgent and elective care triad, as illustrated in Figure 1.25,26,27 For patients with chronic illnesses, this categorization of recommended situations may have some worthy particularities, since the severity of the systemic conditions overlaps dental needs. This is because dental intervention may contribute to overall health improvement and/or prevent the risk of systemic aggravation. ${ }^{10-13}$

At the hospital, dental care may be performed in an outpatient clinic or at bedside. It is preferable to perform dental procedures in an outpatient clinic, because of the physical barriers and specific safety protocols in this environment. When patients cannot

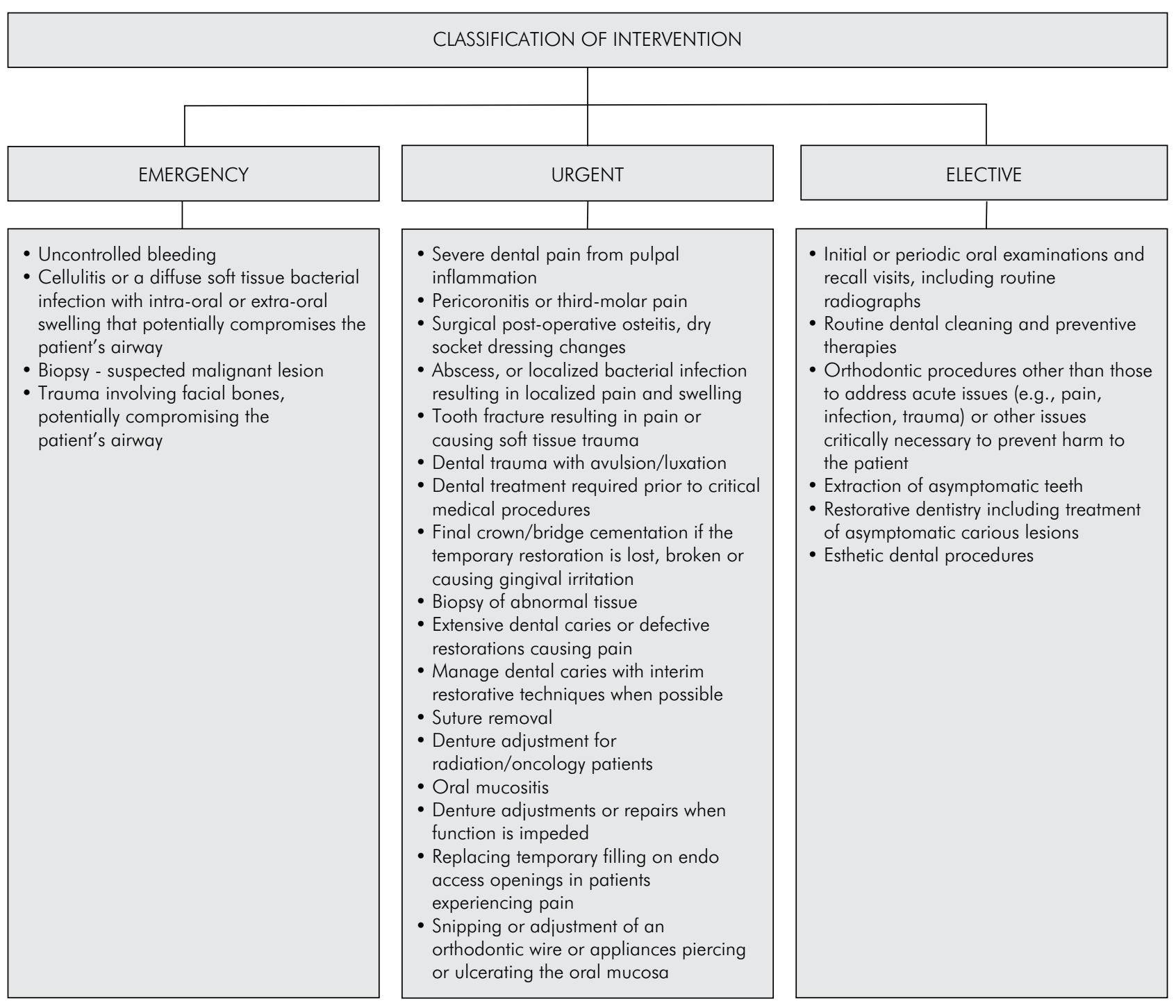

Figure 1. Types of procedures to be performed on hospitalized patients or outpatients by the dentist in a hospital environment. 
be transported to the dental office, dental interventions at bedside are indispensable to address specific needs. This treatment focuses on controlling the focus of infections before, during and after transplantation, as well as chemotherapy and/or radiotherapy, in order to prevent complications. The procedures that generate aerosols at the hospital bed should be used only under specific circumstances, owing to the high risk of contamination of the medical team, other patients, and patients' companions. When put into place, they must be well planned, and include disinfection protocols.

\section{Planning dental appointments and categorizing treatments}

\section{Screening of patients, parents, or guardians}

The patient's anamnesis should preferably be performed remotely by phone or video call (i.e., teledentistry) one day before the appointment. If the patient does not have flu-like symptoms or a positive COVID-19 result, his in-person consultation will be confirmed. At the appointment, a health professional or staff member wearing complete PPE should check the patient's temperature before he enters the dental office and makes contact with any member of the dental team. The following checklist should be completed:

a. Do you have a fever, or have you felt hot or feverish recently (14-21 days)?

b. Have you been experiencing shortness of breath or other difficulties breathing?

c. Have you experienced recent loss of taste or smell?

d. Have you come into contact with any confirmed COVID-19 positive patient or patients?

e. Have you traveled to any regions affected by COVID-19 in the past 14 days?

Positive responses to any of these options certainly call for a more in-depth discussion with the dentist before proceeding with the dental treatment. Patients are referred to a consultation by teledentistry in order to define the type of care needed, and to give them guidance on how to go about conducting isolation at home, according to recommendations by the WHO. ${ }^{28}$ Remember to maintain patient confidentiality. Remind patients/guardians to limit the number of extra companions for special care patients and children on their trip to the dental office, and seek to reduce the number of individuals in the reception area. All patients, parents or guardians should wear surgical masks. The screening of the dental team professionals, whether staff, teachers, students, or collaborators, should be performed daily to determine any symptoms and body temperature (considering a feverish state $\geq 37.8^{\circ} \mathrm{C}$ ), before the clinical activities begin. ${ }^{29}$

\section{Reception area preparation strategies}

Everyone should be reminded of the required hand hygiene and cough etiquette procedure. Provide a hand sanitizing station after entering the facility, with a notice for individuals to use the material before entering the office. Prepare the waiting area, bathrooms, and patient's consultation rooms. If the waiting room has toys, reading materials, or other items, remove or clean them regularly. All surfaces should be cleaned with detergent or soap and water before disinfection.

Ideally, the patient flow should be unidirectional, i.e., defining an entrance and an exit. If this is not possible, the interval between one patient and the other should be longer. Provisions should be made in the event that the presence of more than one patient and/or companion cannot be avoided in the same room. In this respect, the waiting room must be suitably laid out, and the chairs should be spaced at least 1 meter apart. ${ }^{27,29}$

\section{Methods for reducing airborne contamination}

The use of personal barrier protection, such as masks, gloves, eye protection, cap, and gown will eliminate much of the danger from drops splashed from the operation site. A true aerosol or droplet nucleus may remain in the air of the surgical environment for up to 30 minutes after a procedure. ${ }^{23}$ Hence, in the event that the operator removes a protective barrier, such as a face mask, to speak to a patient after the procedure has been concluded, the potential for coming into contact with air-contaminated material remains. In addition, an airborne contaminant might enter the ventilation system, and spread to areas where the barrier protection is not used. ${ }^{20}$

The most commonly cited methods for removing airborne contaminants from the treatment room are 
the use of high-efficiency particulate air filters, and ultraviolet chambers in the ventilation system. ${ }^{20}$ Another system is the high-volume evacuator (HVE), a suction device that draws in a large volume of air over a period of time. The standard HVE device used in dentistry has a large opening, and is connected to an evacuation system that removes an air volume of up to 100 cubic feet per minute. HVE devices has been found to reduce aerosols and splashes from contamination sites by up to $90 \%{ }^{30,31}$ If an HVE or equivalent system cannot be used, the environment of the dental office must be ventilated.

\section{Dental procedures for minimizing airborne contamination}

Since providers work indoors, strategies are needed to reduce the risk inherent in overhead transmission of contaminants, as listed below:

a. Use a rubber dam whenever the procedure allows. When isolation is not possible, give preference to hand instruments and use extractors (e.g., curettes, chisels, sickles, hoes, and periodontal files), instead of ultrasonic devices, to minimize the generation of aerosols.

b. Use high-powered dental suckers. Four-handed work should be encouraged to control dissemination.

c. Avoid using a triple syringe in spray form, activated by pressing the two buttons at the same time. Adjust the cooling water outlet.

d. Pre-clean the patient's mouth by mechanical means, and wash his mouth with an antiseptic.

\section{Methods for reducing surface contamination}

There are many techniques that reduce the risk of viral infection on surfaces, including heat sterilization, chemical disinfectants, and ultraviolet germicidal irradiation (UVGI). ${ }^{32,33}$ Among the various types of products that can be used against SARS-CoV-2, the following are the more common: quaternary ammonium, hydrogen peroxide, peroxyacetic acid, isopropanol, sodium hypochlorite, octanoic acid, L-lactic acid, glycolic acid, phenol, silver ion, citric acid, ethanol, sodium chlorite, hypochlorous acid, and others. ${ }^{33,34}$ It's noteworthy to mention that some materials cannot be sterilized by heat or chemicals. ${ }^{33}$ However, only limited information is available on the effectiveness of UVGI in inactivating viruses on surfaces. A study demonstrated that the effects of UVGI on virus inactivation of surfaces depended on the UV dose. Thus, the effectiveness of UVGI depended heavily on a type of virus nucleic acid. ${ }^{35}$ Regarding SARS-CoV-2, further studies are needed to determine virus susceptibility to UVGI.

Reusable PPE (e.g., safety glasses and face shields) should be cleaned with soap and water between patient consultations, or cleaned and disinfected if visibly dirty. Kohn etal. ${ }^{36}$ recognize that the dental community requires clear and consistent guidelines about the best way to reprocess dental handpiece devices between patient visits. At the end of each procedure, the handpieces must be heat sterilized, and other intraoral instruments must be sanitized with appropriate disinfectants. This recommendation is based on studies showing that the internal components of air-driven dental handpieces can be contaminated during use, and that this contamination can be expelled into the environment of the next patients during subsequent use. ${ }^{37,38}$

Routine cleaning and disinfection procedures for SARS-CoV-2 (e.g., cleaning products used in water to pre-clean surfaces before applying a US Environmental Protection Agency (EPA)-registered hospital-grade disinfectant to frequently touched surfaces or objects, as indicated on the product label) are recommended in healthcare settings, including chairs, desks, door handles, bathrooms, and elevators, especially in aerosol generation areas. ${ }^{34}$

\section{PPE}

PPE is commonly used in healthcare facilities, such as hospitals, dental offices, doctors' offices, and clinical laboratories. Dental care must be provided with advice on strict personal protection and measures to reduce and prevent the production of droplets and aerosols. The use of protective clothing units is recommended, especially helmets, gloves, face shields, safety glasses, respirators, shoes made of plastic material, or other equipment designed to protect the user from injury, or the spread of infection or disease.

\section{Surgical masks and N95/PFF2 respirator masks}

Surgical masks do not provide complete protection against germs and other contaminants, because of the 
loose fit between the surface of the mask and the face. ${ }^{39}$ The indication of wearing a surgical mask for dentistry in a hospital and outpatient setting is an administrative concern, and can be considered unnecessary for any activity that does not involve contact at a distance of less than 1 meter from the patient. ${ }^{40}$

In hospital and outpatient areas, the N95 or PFF2 or PFF3 mask, or equivalent, is recommended for any dental procedure performed, including oral evaluation. ${ }^{25,29}$ In addition, the CDC recommends that health professionals who provide care in intensive and semi-intensive care units should wear a mask (N95 or FFP2 or FFP3 or equivalent). ${ }^{41}$ In procedures in which aerosols will be generated, the mask of choice is the N95 or PFF2, because it offers the best protection. ${ }^{40}$ Given the scarcity of equipment for frontline staff worldwide, a study stated that there is sufficient evidence to endorse the disinfection and possible reuse of respirators with N95 filter masks and other PPE in the current scenario of the pandemic, when needed. ${ }^{32}$

Respiratory protection devices are critical to protecting healthcare professionals at high risk for SARS-CoV-2 against infections. ${ }^{40}$ The virus measures about $120 \mathrm{~nm}(0.12 \mu \mathrm{m})$, and an aerosol particle size ranges from 3 to $100 \mathrm{~nm}$. In 2008, the Health and Safety Executive evaluated the protection offered by different types of masks against influenza bioaerosols, and recommended the use of class FFP3 disposable respirators when performing clinical procedures such as dental drilling, which is expected to generate aerosols of respiratory secretions from infected patients. The use of an FFP3 respirator, for instance, provides a $99 \%$ filtration rate of all particles measuring up to $0.6 \mu \mathrm{m} .^{42}$

The CDC and the European Centre for Disease and Prevention (ECDC) have recommended the N95 respirator for routine non-aerosol-generating care for individuals with COVID-19, while the WHO and the Public Health Agency of Canada have recommended medical masks. ${ }^{24,28,34,43}$ A systematic review compared medical masks (surgical masks) and N95 respirators used to prevent against COVID-19 in healthcare professionals who perform aerosol generation procedures, and N95 respirators were unanimously recommended by national and international guidelines. ${ }^{40}$

\section{Face shield}

The face shield provides barrier protection for the facial area and related mucous membranes (eyes, nose, and lips). The shield should be used as a barrier protection for these anatomical regions against airborne body fluids (e.g., blood, saliva, bronchial secretions, and vomiting) ${ }^{44}$ Visors made of acetate, propionate and polycarbonate offer greater visual clarity and optical quality, as well as the potential to reduce eye fatigue. ${ }^{44}$ Face shields with visors treated for anti-glare, anti-static and anti-fog properties should be preferred. Protection against infectious agents can be enhanced with face shields that cover at least the full length of the face, and have outer edges that extend across the face at least from ear to ear. Protection should also include chin and forehead protectors, and cover the forehead. ${ }^{41}$ Face shields should not function as primary respiratory protection, or be used alone, because aerosols can flow behind the visor, ${ }^{45}$ therefore strongly urging that a protective face mask (medical/surgical mask, N95, PFF2) be worn simultaneously. ${ }^{44}$

\section{Surgical gowns, gloves, cap, and shoes}

Some authorities have recommended the use of long-sleeved water-resistant clothing when caring for patients with COVID-19.34,41,46 The design of the surgical gowns and insulation is based on where the liquid is most likely to make contact (critical zones), and on the likely degree of contact. Since all surgical gowns are expected to come into direct contact with blood, body fluids and pathogens, the entire gown - including the seams - should achieve barrier performance. ${ }^{47}$ Considering that there are various levels of performance for clothes and coveralls, one cannot simply conclude that a certain gown is more protective than the other. The appropriate level of protection for the gown should be chosen according to the assessed risk of exposure and type of contact, as well as the duration and type of procedure to be conducted. ${ }^{27,48}$ However, no study has compared the effectiveness of gowns and coveralls in reducing the transmission of the virus to healthcare professionals. Thus, clothes and coveralls are generally considered acceptable and effective.

Completing the array of PPE, disposable gloves (nitrile or latex) are recommended to perform the 
various procedures to be conducted, but do not replace hand washing. Use of a cap is also mandatory to avoid contamination of the hair. Likewise, shoes made of plastic are recommended (considering our practice of cleaning and disinfecting shoes at the entrance and exit of the surgical environment with $0.05 \%$ quaternary ammonium for 5 minutes). Table depicts the type of PPE used in different dental care areas of the hospital.

\section{Use of mouthwashes}

The use of mouthwashes has been found to be effective in reducing the microbial count in the oral cavity ${ }^{49}$ Pre-procedure mouthwashes may be used to decrease the number of microorganisms in dental aerosol. ${ }^{50,51} \mathrm{~A}$ systematic review reported that there is moderate evidence regarding the efficacy of the chlorhexidine, cetylpyridinium chloride, and essential oils contained in pre-processed mouthwashes, in reducing the number of viable bacteria in the aerosol generated by different dental procedures. ${ }^{49}$ A study documented that chlorhexidine promoted a significantly greater reduction in aerosolized bacteria than essential oils. ${ }^{52}$ Concerning the use of mouthwashes against SARS-CoV-2 before clinical practice, there is currently insufficient evidence to come to any conclusion. ${ }^{53}$

Mouthwashes considered to be effective against SARS-CoV-2 have been recommended based on studies using disinfectant substances on the surface.
Relying on collateral inference, we find references to cetylpyridinium chloride (quaternary ammonium), hydrogen peroxide, and povidone (oxidants) in the literature. ${ }^{54}$ According to this premise, a rinse containing these substances has been proposed for use in the pre-procedure in order to reduce the viral load in the aerosol, and consequently decrease the risk of contamination of health professionals during manipulation of the oral cavity. This recommendation was based on clinical experience obtained in Spain..$^{55}$ Although use of chlorhexidine as a mouthwash may not be effective in killing SARS-CoV-2, ${ }^{25,26}$ a study with only two individuals revealed that the viral load in saliva decreased transiently for two hours after using this antiseptic. ${ }^{56}$ In this context, the use of mouthwashes remains under investigation, and those containing povidone, ${ }^{55} 1 \%$ hydrogen peroxide, ${ }^{57} 0.05 \%$ quaternary ammonium, ${ }^{58} 0.12 \%$ chlorhexidine, ${ }^{56}$ and $\beta$-cyclodextrin combined with citrox ${ }^{59}$ are indicated until randomized clinical trials can be published to demonstrate their effectiveness more conclusively.

\section{Outpatient dental treatment}

The dental treatment for both outpatients and hospitalized patients was stratified into categories ${ }^{48}$ to facilitate patient guidance strategies, as follows:

a. Oral care guidance: oral hygiene. Hand washing before manipulation of the oral cavity for tooth brushing and flossing, in order to avoid contamination by the virus.

Table. Personal protective equipment proposed against COVID-19.

\begin{tabular}{|c|c|c|c|c|c|c|c|c|}
\hline Protection type & $\begin{array}{l}\text { Hand } \\
\text { hygiene }\end{array}$ & $\begin{array}{c}\text { Waterproof } \\
\text { apron }\end{array}$ & Cap & $\begin{array}{c}\text { Surgical } \\
\text { mask }\end{array}$ & $\begin{array}{c}\text { N95/ } \\
\text { PFF2 masks }\end{array}$ & $\begin{array}{l}\text { Glasses or } \\
\text { face protector }\end{array}$ & Gloves & $\begin{array}{c}\text { Appropriate } \\
\text { shoes }\end{array}$ \\
\hline \multicolumn{9}{|l|}{ Dental staff } \\
\hline Administrative/receptionist & & & & $\checkmark$ & & $\checkmark$ & & \\
\hline Screening patients & $\checkmark$ & $\checkmark$ & $\checkmark$ & & $\checkmark$ & $\checkmark$ & $\checkmark$ & \\
\hline Anamnesis & $\checkmark$ & $\checkmark$ & $\checkmark$ & & $\checkmark$ & $\checkmark$ & $\checkmark$ & \\
\hline Radiology services & $\checkmark$ & $\checkmark$ & $\checkmark$ & & $\checkmark$ & $\checkmark$ & $\checkmark$ & \\
\hline Dental assistance without generating aerosol & $\checkmark$ & $\checkmark$ & $\checkmark$ & & $\checkmark$ & $\checkmark$ & $\checkmark$ & \\
\hline Dental assistance with aerosol generation & $\checkmark$ & $\checkmark$ & $\checkmark$ & & $\checkmark$ & $\checkmark$ & $\checkmark$ & \\
\hline Asymptomatic individuals & $\checkmark$ & $\checkmark$ & $\checkmark$ & & $\checkmark$ & $\checkmark$ & $\checkmark$ & \\
\hline Outpatient care & $\checkmark$ & $\checkmark$ & $\checkmark$ & & $\checkmark$ & $\checkmark$ & $\checkmark$ & $\checkmark$ \\
\hline Ward & $\checkmark$ & $\checkmark$ & $\checkmark$ & & $\checkmark$ & $\checkmark$ & $\checkmark$ & $\checkmark$ \\
\hline Individuals with COVID-19 & $\checkmark$ & $\checkmark$ & $\checkmark$ & & $\checkmark$ & $\checkmark$ & $\checkmark$ & \\
\hline Intensive care unit & $\checkmark$ & $\checkmark$ & $\checkmark$ & & $\checkmark$ & $\checkmark$ & $\checkmark$ & $\checkmark$ \\
\hline
\end{tabular}


b. Urgency/emergency treatment: to be performed regularly.

c. Oropharyngeal decontamination treatment: indicated in procedures that produce aerosol, for dental pre-procedures and for oral hygiene.

d. Patients under mechanical ventilation: patients receiving preventive treatment of ventilator-associated pneumonia should be regarded as COVID-19 patients.

Strict adherence to all precautions described by the $\mathrm{CDC}^{24}$ and the $\mathrm{ADA}^{25}$ is recommended as a guideline. It is important to note that there is an indefinite risk for asymptomatic patients, particularly in regions with high transmission rates (5 per 100,000 inhabitants). ${ }^{24}$ These risks to health professionals can be minimized, prevented or reduced by adopting PPE. When the patient arrives at the clinic for face-to-face screening, he will again answer the questions asked in the remote screening (see above). The risk will be suspected if the patient responds positively to any of the questions. Subsequently, screening should be performed to define non-emergency dental procedures or urgent/emergency dental procedures.

If the patient is symptomatic, he should be submitted directly to the rapid/RT-PCR test. If the result is negative, or the patient does not present or report signs and symptoms of SARS-CoV-2, the elective and dental emergency/urgency procedures should be performed by a dentist with protection level 3 (use of PPE) in an isolated room (preferential treatment), and treatment 2, 3 categories should be adopted. However, if the patient's result is positive, or if screening confirms COVID-19 infection, the signs and symptoms of acute respiratory distress syndrome (ARDS) must be evaluated, such as: $\mathrm{SpO}_{2}<92 \%, \mathrm{RR}>22 / \mathrm{min}$, hypotension, and signs of difficulty breathing. If the patient shows the above clinical changes, he should be referred for medical evaluation, and his case should be reported to the hospital. If the patient does not present ARDS symptoms, dental emergency/urgency procedures should be performed by a dentist with protection level 3 (use of PPE) in an isolated room, and treatment 2, 3 categories should be incorporated. The following procedure should be adopted in either case (negative or positive status without ARDS signs): if the patient's treatment ends after the procedure, then the treatment 1 category should be endorsed, but if treatment did not end, the patient must undergo all the screening levels upon his return to continue treatment.

\section{Hospital dental assistance}

The management of individuals with COVID-19 can be performed during hospitalization. SARS-CoV-2 is known to cause substantial lung disease, including pneumonia and ARDS. Extrapulmonary manifestations affecting various organs and systems have been documented, such as hematological, cardiovascular, renal, gastrointestinal, hepatobiliary, endocrinological, neurological, ophthalmological, and dermatological conditions. ${ }^{60}$

The Sepsis Survival Campaign (SSC) COVID-19 recommends performing aerosol generation procedures in patients with COVID-19 in a negative pressure room (statement of recommended practice), with fitted breathing masks (N95, FFP2 respirators or equivalent), and an additional type of PPE (i.e., gloves, lab coat and eye protection, such as a face mask or safety glasses). ${ }^{61}$

COVID-19 patients may have several laboratory abnormalities (lymphopenia, leukocytosis, neutrophilia, and thrombocytopenia). In addition, an increased erythrocyte sedimentation rate, C-reactive protein, ferritin, IL-6, and lactate dehydrogenase have been described. Moreover, altered coagulation indices, high D-dimer and fibrinogen, prolonged prothrombin time, and partial thromboplastin time have been reported. Thromboembolic complications were first reported in intensive care units in China ${ }^{62}$ and in the Netherlands ${ }^{63}$ in up to $30 \%$ of the patients (arterial occlusive disease and other vascular events, including acute myocardial infarction, acute limb ischemia and stroke, in severely affected individuals). ${ }^{60}$

At the hospital, many patients with COVID-19 who need dental care should be classified according to the medical and dental emergency/urgency. If there is no dental or medical emergency, regular treatment and elective procedures should be postponed until after the end of quarantine, at which time category 1 treatment will be initiated, as shown in Figure 2. 


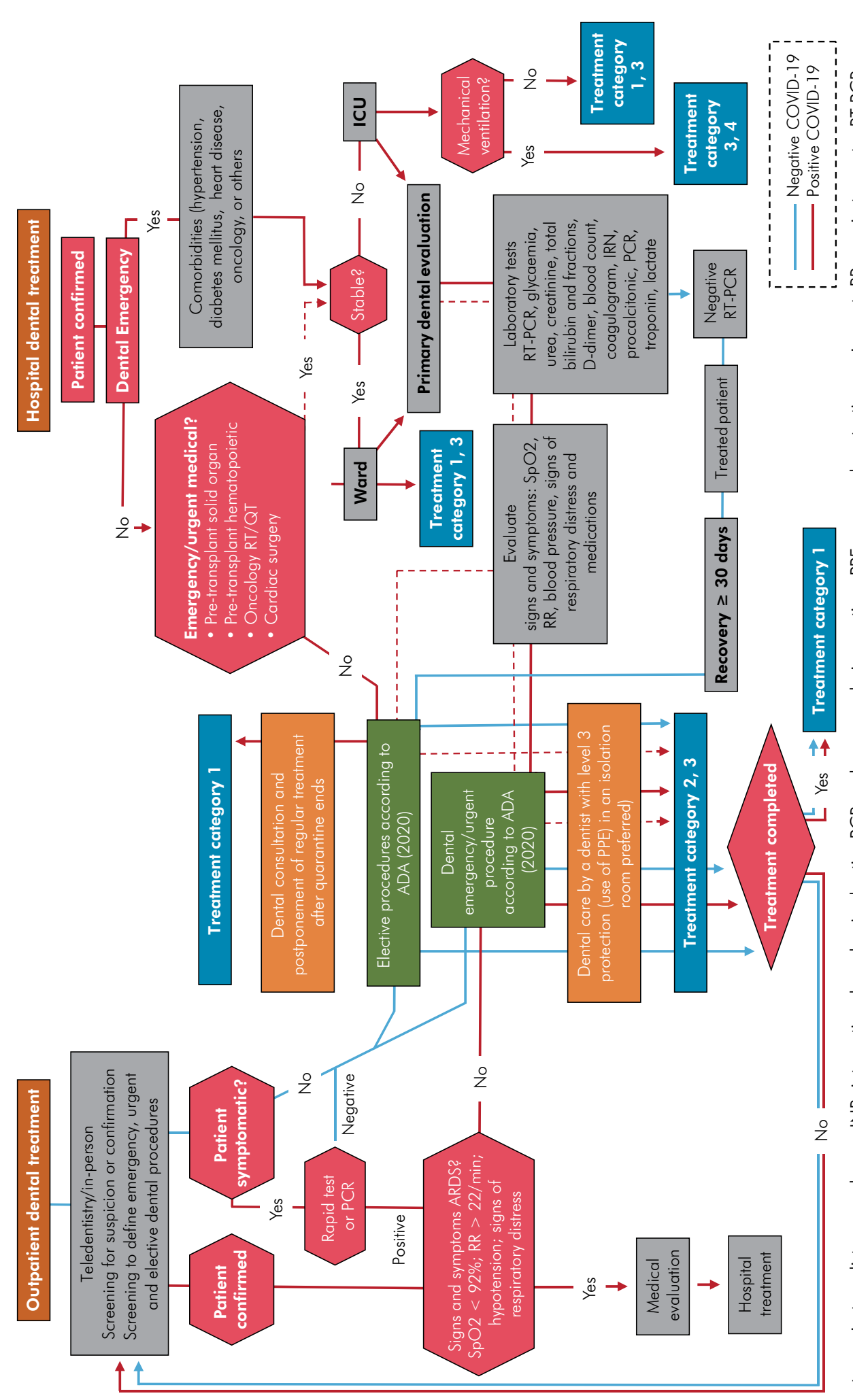

出

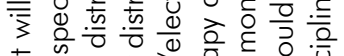

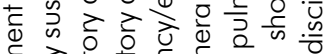

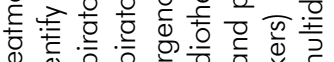

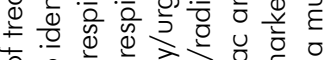
to

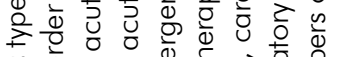
婇 ष्ग

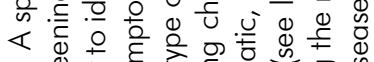

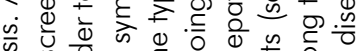

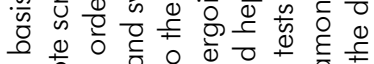

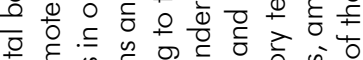

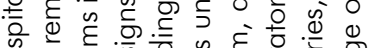
栲

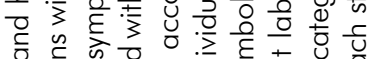

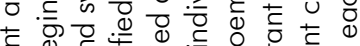

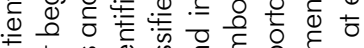

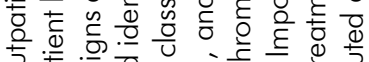
万人 б

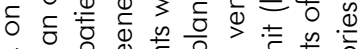

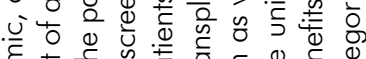
है

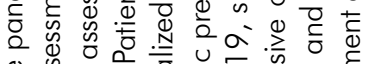

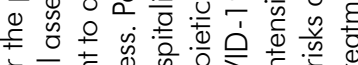

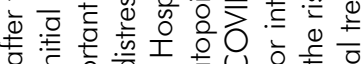

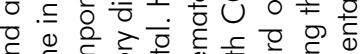

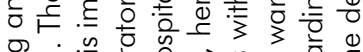

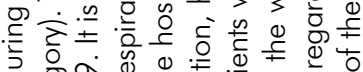
ว응

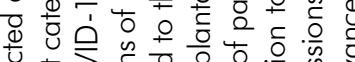

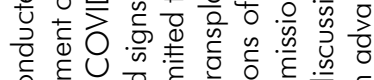

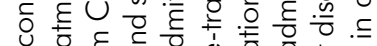

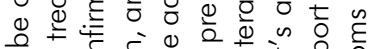

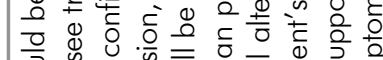

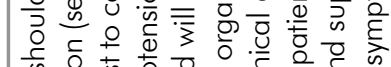
的. 운

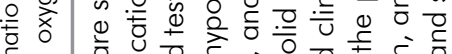

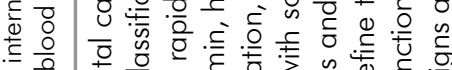

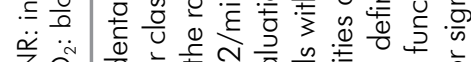
岂告

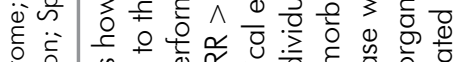
은

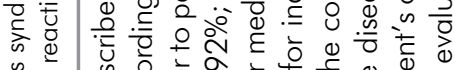
岁. 旁它

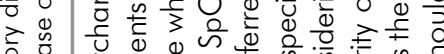

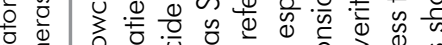

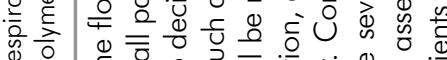

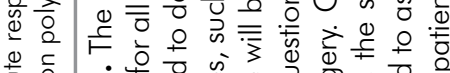
㽦.

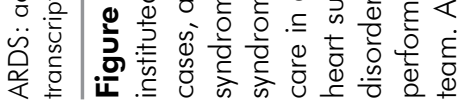


A COVID-19 patient needing oral adequacy for a pre-transplant solid organ, pre-transplant hematopoietic organ, radiotherapy/chemotherapy, or heart surgery is categorized as a medical emergency/urgency. Hence, dental care by a dentist with protection level 3 (use of PPE) in an isolation room, and routine treatment and category 3 treatment is instituted.

Nonetheless, it is essential to know whether the patient is clinically stable. We must recognize his clinical condition. Is it stable? If the answer is "yes," the patient will undergo clinical treatment in the ward. To this end, the patient will receive an assessment from the primary dentist to determine his dental needs, and to initiate category 1, 3 treatments immediately. In addition, it is imperative to evaluate any laboratory markers of abnormal cell counts, such as lymphopenia, leukocytosis, neutrophilia, thrombocytopenia, and any elevation of serum inflammatory markers such as C-reactive protein, rate, and D-dimer. In addition, lactate dehydrogenase is predictive of subsequent critical illness and mortality in patients with COVID-19. Higher serum levels of IL-6 have also been linked to a worse prognosis, and have been found to correlate with fibrinogen levels in patients with COVID-19. Troponin elevation in hospitalized patients has been associated with more severe diseases and worse outcomes when measuring troponin concentrations to identify acute myocardial infarction. The prevalence of elevated serum creatinine, elevated urea nitrogen in blood, and an estimated glomerular filtration rate below $60 \mathrm{ml} / \mathrm{min} / 1.73 \mathrm{~m}^{2}$ has shown that patients with kidney disease have a significantly higher risk of in-hospital death. Increased procalcitonin values seem to have a role in predicting patient evolution toward a more severe form of the disease. Elevated hepatic transaminases and elevated bilirubin levels are linked to progression toward liver damage. ${ }^{60,62,63}$ The case of the COVID-19 patient should be discussed by a multidisciplinary team, and then the procedure should be scheduled and performed in an isolated room. During hospitalization, laboratory tests are performed frequently, including RT-PCR. When the patient has a negative RT-PCR, dental care may be performed normally after 30 days. ${ }^{64}$
If the patient shows signs and symptoms of clinical instability, he will be admitted to the intensive care unit. Is mechanical ventilation necessary? If "yes", institute category 3, 4 treatments. If "no", institute category 1, 3 treatments. The patient in an intensive care unit who needs dental treatment will be submitted to primary dental evaluation, and the flow of care will be the same for patients admitted to the ward. Usually, what changes is the severity of the patient's case, and/or the presence of an endotracheal tube. In this case, the discussion of the cases to be seen to must be detailed. SSC-COVID-19 recommends that supplemental oxygen should be administered in adults with COVID-19, if $\mathrm{SpO}_{2}$ is $<92 \%$ or $<90 \%$. In adult patients with COVID-19 and acute hypoxemic respiratory failure with oxygen therapy, it is recommended that $\mathrm{SpO}_{2}$ should not be maintained above $96 \%$. Dental intervention is a borderline decision. In some cases, the patient must be stabilized before he can receive dental care.

\section{Conclusion}

In summary, COVID-19 has represented a major change in dental clinical practice, mainly in hospital services. In this article, we discussed our experience at the Hospital das Clínicas in Belo Horizonte, a public referral service supported by the Brazilian National Health System and at the forefront of COVID-19 care. Although face-to-face consultations must be reduced in order to decrease the risk of infection, clinicians must ensure a continuum of care, especially for patients with critical systemic diseases, and with urgent dental demands. The high exposure of dentists who are on the frontline against COVID-19 requires providers to follow essential precautionary practices that are crucial to their protection and to that of their relatives and patients during the pandemic. In addition, universal measures must be adopted in view of the sizable proportion of asymptomatic individuals, and the difficulty in tracing disease-related data in Brazil and worldwide.

\section{Acknowledgments}

This study was supported by Coordenação de Aperfeiçoamento de Pessoal de Nível Superior 
(Funding Code 001), Brazil. J.A.A.A. is the recipient of a fellowship. We would like to thank Conselho Nacional de Desenvolvimento Científico e Tecnológico (CNPq), Brazil. T.A.S. is a research fellow at CNPq. Mrs. E. Greene provided English editing for the manuscript.

\section{References}

1. World Health Organization. Timeline of WHO's response to COVID-19. Geneva: World Health Organization; 2020 [cited 2020 Jul 12]. Available from: https://www.who.int/news-room/detail/29-06-2020-covidtimeline

2. Zhou $P$, Yang XL, Wang XG, Hu B, Zhang L, Zhang W, et al. A pneumonia outbreak associated with a new coronavirus of probable bat origin. Nature. 2020 Mar;579(7798):270-3. https://doi.org/10.1038/s41586-020-2012-7

3. Rodriguez-Morales AJ, Gallego V, Escalera-Antezana JP, Méndez CA, Zambrano LI, Franco-Paredes C, et al. COVID-19 in Latin America: the implications of the first confirmed case in Brazil. Travel Med Infect Dis. 2020 May - Jun;35:101613. https://doi.org/10.1016/.tmaid.2020.101613

4. Candido DS, Claro IM, Jesus JG, Souza WM, Moreira FR, Dellicour S, et al. Evolution and epidemic spread of SARS-CoV-2 in Brazil. Science. 2020 Sep;369(6508):1255-60. https://doi.org/10.1126/science.abd2161

5. Alves FA, Saunders D, Sandhu S, Xu Y, de Mendonça NF, Treister NS. Implication of COVID-19 in oral oncology practices in Brazil, Canada, and the United States. Oral Dis. 2021 Apr;27 Suppl 3:793-5. https://doi.org/10.1111/odi.13493

6. Kinariwala N, Samaranayake LP, Perera I, Patel Z. Concerns and fears of Indian dentists on professional practice during the coronavirus disease 2019 (COVID-19) pandemic. Oral Dis. 2021 Apr;27 Suppl 3:730-2. https://doi.org/10.1111/odi.13459

7. Ing EB, Xu QA, Salimi A, Torun N. Physician deaths from corona virus (COVID-19) disease. Occup Med (Lond). 2020 Jul;70(5):370-4. https://doi.org/10.1093/occmed/kqaa088

8. Nienhaus A, Hod R. COVID-19 among Health Workers in Germany and Malaysia. Int J Environ Res Public Health. 2020 Jul;17(13):4881. https://doi.org/10.3390/ijerph17134881

9. Kochhar AS, Bhasin R, Kochhar GK, Dadlani H. Provision of continuous dental care for oral oncology patients during \& after COVID-19 pandemic. Oral Oncol. 2020 Jul;106:104785. https://doi.org/10.1016/j.oraloncology.2020.104785

10. Berkey DB, Scannapieco FA. Medical considerations relating to the oral health of older adults. Spec Care Dentist. 2013 Jul-Aug;33(4):164-76. https://doi.org/10.1111/scd.12027

11. Thanvi J, Bumb D. Impact of dental considerations on the quality of life of oral cancer patients. Indian J Med Paediatr Oncol. 2014 Jan;35(1):66-70. https://doi.org/10.4103/0971-5851.133724

12. Jawad $\mathrm{H}$, Hodson NA, Nixon PJ. A review of dental treatment of head and neck cancer patients, before, during and after radiotherapy: part 1. Br Dent J. 2015 Jan;218(2):65-8. https://doi.org/10.1038/sj.bdj.2015.28

13. Jawad $\mathrm{H}$, Hodson NA, Nixon PJ. A review of dental treatment of head and neck cancer patients, before, during and after radiotherapy: part 2. Br Dent J. 2015 Jan;218(2):69-74. https://doi.org/10.1038/sj.bdj.2015.29

14. Santos JA, Normando AG, Silva RCL, Acevedo AC, Canto GL, Sugaya N, et al. Oral manifestations in patients with COVID-19: a living systematic review. J Dent Res. 2021 Feb;100(2):141-54. https://doi.org/10.1177/0022034520957289

15. Lu CW, Liu XF, Jia ZF. 2019-nCoV transmission through the ocular surface must not be ignored. Lancet. 2020 Feb;395(10224):e39. https://doi.org/10.1016/S0140-6736(20)30313-5

16. Jamal M, Shah M, Almarzooqi SH, Aber H, Khawaja S, El Abed R, et al. Overview of transnational recommendations for COVID-19 transmission control in dental care settings. Oral Dis. 2021 Apr;27 Suppl 3:655-64. https://doi.org/10.1111/odi.13431

17. To KK, Tsang OT, Yip CC, Chan KH, Wu TC, Chan JM, et al. Consistent Detection of 2019 Novel Coronavirus in Saliva. Clin Infect Dis. 2020 Jul;71(15):841-3. https://doi.org/10.1093/cid/ciaal49

18. Xu R, Cui B, Duan X, Zhang P, Zhou X, Yuan Q. Saliva: potential diagnostic value and transmission of 2019-nCoV. Int J Oral Sci. 2020 Apr;12(1):11. https://doi.org/10.1038/s41368-020-0080-z

19. Zaid W, Schlieve T. the early effects of Coronavirus disease-2019 on head and neck oncology and microvascular reconstruction practice: a national survey of oral and maxillofacial surgeons enrolled in the Head and Neck Special Interest Group. J Oral Maxillofac Surg. 2020 Oct;78(10):1859-68. https://doi.org/10.1016/i.joms.2020.07.012

20. Harrel SK, Molinari J. Aerosols and splatter in dentistry: a brief review of the literature and infection control implications. J Am Dent Assoc. 2004 Apr;135(4):429-37. https://doi.org/10.14219/jada.archive.2004.0207

21. Fennelly KP. Particle sizes of infectious aerosols: implications for infection control. Lancet Respir Med. 2020 Sep;8(9):914-24. https://doi.org/10.1016/S2213-2600(20)30323-4

22. Veena HR, Mahantesha S, Joseph PA, Patil SR, Patil SH. Dissemination of aerosol and splatter during ultrasonic scaling: a pilot study. J Infect Public Health. 2015 May-Jun;8(3):260-5. https://doi.org/10.1016/i.jiph.2014.11.004 
- Safety protocols for dental care during the COVID-19 pandemic: the experience of a Brazilian hospital service

23. Doremalen N, Bushmaker T, Morris DH, Holbrook MG, Gamble A, Williamson BN, et al. Aerosol and surface stability of HCoV-19 (SARS-CoV-2) compared to SARS-CoV-1. medRxiv [Preprint]. 2020 Mar 13. https://doi.org/10.1101/2020.03.09.20033217

24. Centers for Disease Control and Prevention. Interim infection prevention and control recommendations for healthcare personnel during the Coronavirus disease 2019 (COVID-19) pandemic. Washington, DC: Centers for Disease Control and Prevention; 2020 [cited 2020 Mar 17]. Available from: https://www.cdc.gov/coronavirus/2019-ncov/hcp/infection-control-recommendations.html

25. American Dental Association. ADA releases Interim guidance for minimizing risk of COVID-19 transmission risk When treating dental emergencies. Chicago: American Dental Association; 2020 [cited 2020 Jun 10]. Available from: https://www.ada.org/en/publications/ ada-news/2020-archive/april/ada-releases-interim-guidance-on-minimizing-covid-19-transmission-risk-when-treating-emergencies

26. Ministério da Saúde (BR). Secretaria de Vigilância em Saúde. Nota Técnica GVIMS/GGTES/ANVISA N 04/2020. Orientações para serviços de saúde: medidas de prevenção e controle que devem ser adotadas durante a assistência aos casos suspeitos ou confirmados de infecção pelo novo coronavírus (SARS-CoV-2). 2020 [cited 2020 Sep 16]. Available from: http://portal.anvisa.gov.br/ documents/33852/271858/Nota+T\%C3\%A9cnica+n+04-2020+GVIMS-GGTES-ANVISA/ab598660-3de4-4f14-8e6f-b9341c196b28

27. Association for the Advancement of Medical Instrumentation. AAMI TIR11:2005/(R)2015: Selection and use of protective apparel and surgical drapes in health care facilities. Arlington: Association for the Advancement of Medical Instrumentation; 2015 [cited 2020 Sep 22]. Available from: https://www.aami.org/docs/default-source/products_store/standards/tir11_1510.pdf?sfvrsn=eb81931b_2

28. World Health Organization. Rational use of personal protective equipment for coronavirus disease 2019 (COVID-19). Geneva: World Health Organization; 2020 [cited 2020 Feb 27]. Available from: https://apps.who.int/iris/bitstream/handle/10665/331215/WHO-2019nCov-IPCPPE_use-2020.1-eng.pdf

29. American Dental Association. What constitutes a dental emergency? Chicago: American Dental Association; 2020 [cited $2020 \mathrm{Jul}$ 9]. Available from: https://success.ada.org/ /media/CPS/Files/Open\%20Files/ADA_COVID19_Dental_Emergency_DDS. pdf?utm_source $=$ adaorg\&utm_medium =covid-resources-Ip\&utm_content $=c v-$ pm-emerg-def\&utm_campaign $=$ covid-19\&_ $\mathrm{ga}=2.158719422 .527261862 .1584796909-1982106663.1584563184$

30. Dahlke WO, Cottam MR, Herring MC, Leavitt JM, Ditmyer MM, Walker RS. Evaluation of the spatter-reduction effectiveness of two dry-field isolation techniques. J Am Dent Assoc. 2012 Nov;143(11):1199-204. https://doi.org/10.14219/jada.archive.2012.0064

31. Holloman JL, Mauriello SM, Pimenta L, Arnold RR. Comparison of suction device with saliva ejector for aerosol and spatter reduction during ultrasonic scaling. J Am Dent Assoc. 2015 Jan;146(1):27-33. https://doi.org/10.1016/i.adaj.2014.10.001

32. Derraik JG, Anderson WA, Connelly EA, Anderson YC. Rapid Review of SARS-CoV-1 and SARS-CoV-2 Viability, Susceptibility to Treatment, and the Disinfection and Reuse of PPE, Particularly Filtering Facepiece Respirators. Int J Environ Res Public Health. 2020 Aug;17(17):6117. https://doi.org/10.3390/ijerph17176117

33. Rabenau HF, Kampf G, Cinatl J, Doerr HW. Efficacy of various disinfectants against SARS coronavirus. J Hosp Infect. 2005 Oct;61(2):107-11. https://doi.org/10.1016/i.jhin.2004.12.023

34. European Centre for Disease Prevention and Control. Guidance for wearing and removing personal protective equipment in healthcare settings for the care of patients with suspected or confirmed COVID-19. 2020 [cited 2020 Mar 17]. Available from: https://www.ecdc.europa.eu/sites/ default/files/documents/COVID-19-guidance-wearing-and-removing-personal-protective-equipment-healthcare-settings-updated.pdf

35. Tseng CC, Li CS. Inactivation of viruses on surfaces by ultraviolet germicidal irradiation. J Occup Environ Hyg. 2007 Jun;4(6):400-5. https://doi.org/10.1080/15459620701329012

36. Kohn WG, Harte JA, Malvitz DM, Collins AS, Cleveland JL, Eklund KJ. Guidelines for infection control in dental health care settings_2003. J Am Dent Assoc. 2004 Jan;135(1):33-47. https://doi.org/10.14219/jada.archive.2004.0019

37. Chin JR, Westerman AE, Palenik CJ, Eckert SG. Contamination of handpieces during pulpotomy therapy on primary teeth. Pediatr Dent. 2009 Jan-Feb;31(1):71-5.

38. Herd S, Chin J, Palenik CJ, Ofner S. The in vivo contamination of air-driven low-speed handpieces with prophylaxis angles. J Am Dent Assoc. 2007 Oct;138(10):1360-5. https://doi.org/10.14219/jada.archive.2007.0053

39. Food and Drug Administration. N95 respirators, surgical masks, and face masks. [cited 2020 Jul 8]. Available from: https://www.fda.gov/ medical-devices/personal-protective-equipment-infection-control/n95-respirators-surgical-masks-and-face-masks\#s2

40. Bartoszko JJ, Farooqi MA, Alhazzani W, Loeb M. Medical masks vs N95 respirators for preventing COVID-19 in healthcare workers: a systematic review and meta-analysis of randomized trials. Influenza Other Respir Viruses. 2020 Jul;14(4):365-73. https://doi.org/10.1111/irv.12745

41. Centers for Disease Control and Prevention. Workplace safety \& health topics. eye protection for infection control. Washington, DC: Centers for Disease Control and Prevention [cited 2020 Jul 9]. Available from: http://www.cdc.gov/niosh/topics/eye/eye-infectious.html

42. Health and Safety Executive. Evaluating the protection afforded by surgical masks against influenza bioaerosols: gross protection of surgical masks compared to filtering facepiece respirators. 2008 [cited 2020 Mar 27]. Available from: https://www.hse.gov.uk/research/rrpdf/rr619.pdf

43. Public Health Agency of Canada. Coronavirus disease (COVID-19): for health professionals. 2020 [cited 2020 Mar 18]. Available from: https://www.canada.ca/en/public-health/services/diseases/2019-novel-coronavirus-infection/health-professionals.html\#i

44. Roberge RJ. Face shields for infection control: a review. J Occup Environ Hyg. 2016;13(4):235-42. https://doi.org/10.1080/15459624.2015.1095302 
45. Lindsley WG, Noti JD, Blachere FM, Szalaida JV, Beezhold DH. Efficacy of face shields against cough aerosol droplets from a cough simulator. J Occup Environ Hyg. 2014;11(8):509-18. https://doi.org/10.1080/15459624.2013.877591

46. World Health Organization. Personal protective equipment for use in a filovirus disease outbreak: rapid advice guideline. Geneva: World Health Organization; 2016 [cited 2020 Jun 1]. Available from: https://apps.who.int/iris/handle/10665/251426

47. Park SH. Personal protective equipment for healthcare workers during the COVID-19 pandemic. Infect Chemother. 2020 Jun;52(2):165-82. https://doi.org/10.3947/ic.2020.52.2.165

48. Conselho Federal de Odontologia. Recomendações AMIB/CFO para enfrentamento da COVID-19 na odontologia. Brasília, DF: Conselho Federal de Odontologia; 2020 [cited 2020 Jun 10]. Available from: https://website.cfo.org.br/wp-content/uploads/2020/05/ AMIB_CFO-Recomendac\%cc\%a7o\%cc\%83es.pdf

49. Marui VC, Souto ML, Rovai ES, Romito GA, Chambrone L, Pannuti CM. Efficacy of preprocedural mouthrinses in the reduction of microorganisms in aerosol: A systematic review. J Am Dent Assoc. 2019 Dec;150(12):1015-1026.el. https://doi.org/10.1016/i.adaj.2019.06.024

50. Feres M, Figueiredo LC, Faveri M, Stewart B, de Vizio W. The effectiveness of a preprocedural mouthrinse containing cetylpyridinium chloride in reducing bacteria in the dental office. J Am Dent Assoc. 2010 Apr;141(4):415-22. https://doi.org/10.14219/jada.archive.2010.0193

51. Retamal-Valdes B, Soares GM, Stewart B, Figueiredo LC, Faveri M, Miller S, et al. Effectiveness of a pre-procedural mouthwash in reducing bacteria in dental aerosols: randomized clinical trial. Braz Oral Res. 2017 Mar;31(0):e21. https://doi.org/10.1590/1807-3107bor-2017.vol31.0021

52. Logothetis DD, Martinez-Welles JM. Reducing bacterial aerosol contamination with a chlorhexidine gluconate pre-rinse. J Am Dent Assoc. 1995 Dec;126(12):1634-9. https://doi.org/10.14219/jada.archive.1995.0111

53. Kelly N, Nic ĺomhair A, McKenna G. Can oral rinses play a role in preventing transmission of Covid 19 infection? Evid Based Dent. 2020 Jun;21(2):42-3. https://doi.org/10.1038/s41432-020-0099-1

54. United States Environmental Protection Agency. List N: products with emerging viral pathogens and human coronavirus claims for use against SARS-CoV-2. [cited 2020 Sep 4]. Available from: https://www.epa.gov/pesticide-registration/list-n-disinfectants-use-against-sar s-cov-2]

55. Martínez Lamas L, Diz Dios P, Pérez Rodríguez MT, Del Campo Pérez V, Cabrera Alvargonzalez JJ, López Domínguez AM, et al. Is povidone iodine mouthwash effective against SARS-CoV-2? First in vivo tests. Oral Dis. $2020 \mathrm{Jul}$ 2. https://doi.org/10.1111/odi.13526

56. Yoon JG, Yoon J, Song JY, Yoon SY, Lim CS, Seong H, et al. Clinical significance of a high SARS-CoV-2 viral load in the saliva. J Korean Med Sci. 2020 May;35(20):e195. https://doi.org/10.3346/jkms.2020.35.e195

57. Meister TL, Brüggemann Y, Todt D, Conzelmann C, Müller JA, Groß R, et al. Virucidal efficacy of different oral rinses against severe acute respiratory syndrome coronavirus 2. J Infect Dis. 2020 Sep;222(8):1289-92. https://doi.org/10.1093/infdis/iiaa471

58. Popkin DL, Zilka S, Dimaano M, Fujioka H, Rackley C, Salata R, et al. Cetylpyridinium Chloride (CPC) Exhibits potent, rapid activity against influenza viruses in vitro and in vivo. Pathog Immun. 2017;2(2):252-69. https://doi.org/10.20411/pai.v2i2.200

59. Carrouel F, Conte MP, Fisher J, Gonçalves LS, Dussart C, Llodra JC, et al. COVID-19: a recommendation to examine the effect of mouthrinses with $\beta$-Cyclodextrin combined with citrox in preventing infection and progression. J Clin Med. 2020 Apr;9(4):1126. https://doi.org/10.3390/jcm9041126

60. Gupta A, Madhavan MV, Sehgal K, Nair N, Mahajan S, Sehrawat TS, et al. Extrapulmonary manifestations of COVID-19. Nat Med. 2020 Jul;26(7):1017-32. https://doi.org/10.1038/s41591-020-0968-3

61. Alhazzani W, Møller MH, Arabi YM, Loeb M, Gong MN, Fan E, et al. Surviving Sepsis Campaign: guidelines on the management of critically ill adults with Coronavirus Disease 2019 (COVID-19). Intensive Care Med. 2020 May;46(5):854-87. https://doi.org/10.1007/s00134-020-06022-5

62. Cui S, Chen S, Li X, Liu S, Wang F. Prevalence of venous thromboembolism in patients with severe novel coronavirus pneumonia. J Thromb Haemost. 2020 Jun;18(6):1421-4. https://doi.org/10.1111/jth.14830

63. Klok FA, Kruip MJ, Meer NJ, Arbous MS, Gommers DA, Kant KM, et al. Incidence of thrombotic complications in critically ill ICU patients with COVID-19. Thromb Res. 2020 Jul;191:145-7. https://doi.org/10.1016/j.thromres.2020.04.013

64. Alharbi A, Alharbi S, Alqaidi S. Guidelines for dental care provision during the COVID-19 pandemic. Saudi Dent J. 2020 May;32(4):181-6. https://doi.org/10.1016/j.sdenti.2020.04.001 